Wintgens, T. ; Melin, T. ; Schäfer, A. I. ; Muston, M. ; Bixio, D. ; Thoeye, C. (2005) The role of membrane processes in municipal wastewater reclamation and reuse, Desalination, 178, 1-11 doi:10.1016/j.desal.2004.12.014

\section{The role of membrane processes in municipal wastewater reclamation and reuse}

T. Wintgens, T. Melin (Department of Chemical Engineering, RWTH Aachen University/Germany) A. Schäfer, S. Khan, M. Muston (University of Wollongong/Australia)

D. Bixio, C. Thoeye (Aquafin NV/Belgium)

Contact: Thomas Wintgens, Department of Chemical Engineering, RWTH Aachen University, Turmstrasse 46, 52056 Aachen, Germany, e-mail: wintgens@ivt.rwth-aachen.de, Phone: +49-2418096233, Fax: +49-241-8092252

\section{Abstract}

Wastewater reuse presents a promising solution to the growing pressure on water resources However, wastewater reuse implementation faces obstacles that include insufficient public acceptance, technical, economic and hygienic risks and further uncertainties caused by a lack of awareness, accepted standards, uniform guidelines and legislation. So far, there are no supranational regulations on water reuse in Europe and further development is slowed by lack of widely accepted standards e.g. in terms of required water quality, treatment technology and distribution system design and operation.

Treatment technology encompasses a vast number of options and membrane processes are regarded as key elements of advanced wastewater reclamation and reuse schemes and are included in number of prominent schemes world-wide, e.g. for artificial groundwater recharge, indirect potable reuse as well as for industrial process water production. For dual reticulation purposes in urban areas two types of systems have been built, a centralised type of treatment with dual membrane processes, including e.g. microfiltration (MF) and reverse osmosis (RO), and small scale systems using membrane bioreactors. This paper will provide an overview of the status of membranes processes in wastewater reclamation and reuse world-wide and will depict their potential role in promoting more sustainable water use patterns.

Keywords: wastewater reclamation, water reuse, membrane processes, microfiltration, reverse osmosis

\section{Reclamation and reuse of municipal wastewater - Status}

Reclamation and reuse of municipal wastewater is a very common practice worldwide [1]. By reclaiming wastewater, the circulation of water through the natural water cycle can be shortcircuited, such that a contribution to human water needs is made and the environmental impact thereof limited. Furthermore, a main characteristic of reclaimed wastewater is that its "production" is relatively constant during the year, due to its source being dependent not on rainfall, but on the production of municipal sewage. Thus, reclaimed water can increase the reliability of a water supply, comprising as it does, a further source of water. Similarly, recycled water can be viewed as an independent source of water capable of increasing the reliability of a water supply $[2,3]$. This opportunity has to date been used in various countries using a range of technologies for different water applications. The most common reclamation technologies and reuse applications are illustrated in Figure 1 with the number of water reuse schemes per field of application and the level of treatment - secondary, tertiary or quaternary - attached to them in different regions of the world [1]. Note that wastewater reclamation refers to the treatment or processing of water to make it fit for reuse, which is defined as any kind of beneficial use of reclaimed water [4].

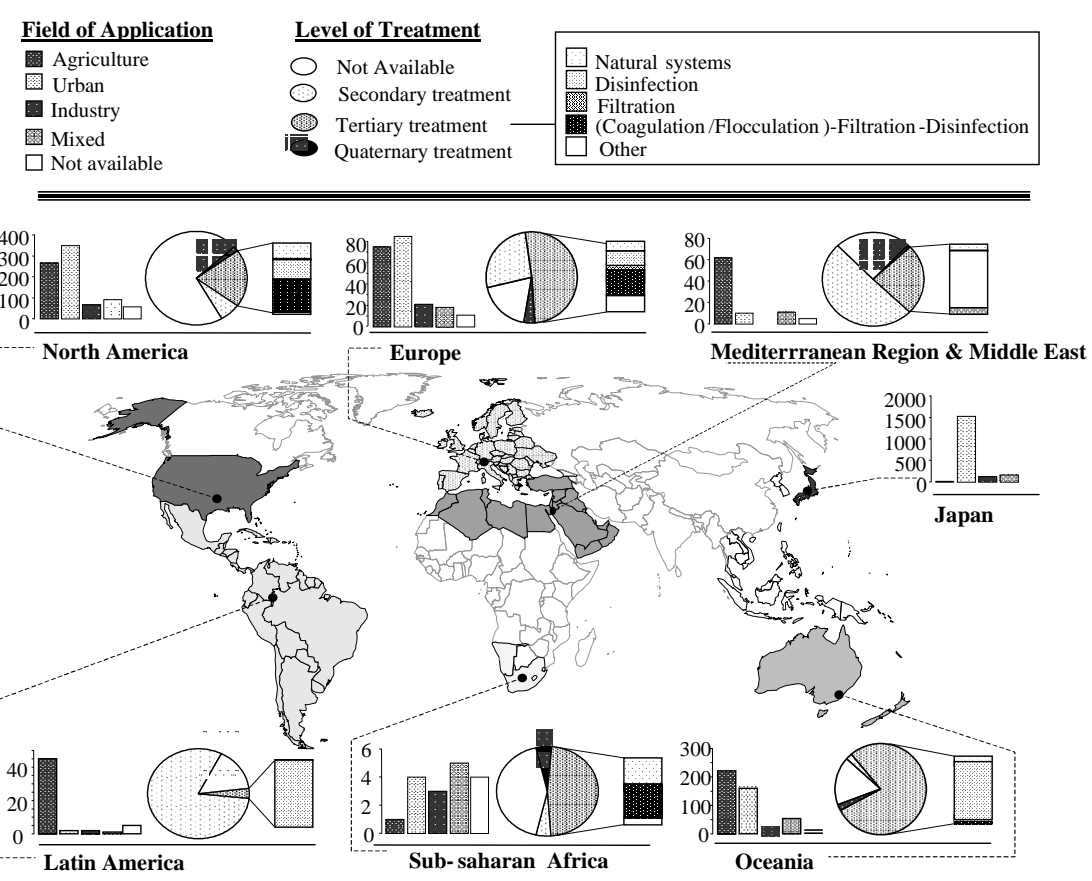

Figure 1: Water reuse schemes per field of application (bar-charts) and level of treatment (pie-charts with attached bar for main tertiary treatment processes) in different regions of the world [1]

A number of definitions require further details; secondary treatment - here also including nutrient removal - is characteristic of restricted agricultural irrigation (i.e. for food crops not consumed uncooked) and for some industrial applications such as industrial cooling (except for the food industry). Additional filtration/disinfection steps (tertiary treatment) are applied for unrestricted agricultural or landscape irrigation as well as for process water in some industrial applications. Quaternary treatment is defined here as a treatment producing a quality comparable to drinking water - often involving a "dual membrane" step to meet unrestricted residential uses and industrial applications requiring ultrapure water. Table 1 lists the main categories of municipal wastewater reuse applications (listed in order of decreasing projected volume of use). 
Wintgens, T. ; Melin, T. ; Schäfer, A. I. ; Muston, M. ; Bixio, D. ; Thoeye, C. (2005) The role of membrane processes in municipal wastewater reclamation and reuse, Desalination, 178, 1-11 doi:10.1016/j.desal.2004.12.014

Table 1: Categories of municipal wastewater reuse plus applications [ 5 ]

\begin{tabular}{|l|l|}
\hline Wastewater reuse category & \\
\hline Cricultural irrigation & Environmental \\
Commercial nurseries & Lakes and ponds \\
& Streamflow augmentation \\
Landscape irrigation & Fisheries \\
Park & Non-potable urban uses \\
Golf course & Fire protection \\
Residential & Air conditioning \\
& Toilet flushing \\
Industrial recycling and reuse & \\
Cooling & Potable reuse \\
Boiler feed & Blending in water supply reservoir \\
Process water & Pipe to pipe water supply \\
& \\
Groundwater recharge & \\
Groundwater replenishment & \\
Salt water intrusion control &
\end{tabular}

\section{Quality requirements for particular uses - Need for membranes?}

Water and wastewater treatment membranes are typically classified in order of decreasing pore size as microfiltration (MF), ultrafiltration (UF), nanofilatration (NF) and reverse osmosis (RO). As a general rule, MF is suitable for the removal of suspended solids, including larger micro-organisms like protozoa and bacteria. UF is required for the removal of viruses and organic macromolecules down to a size of around $20 \mathrm{~nm}$. Smaller organics and multivalent ions may be removed by NF while RO is even suitable for the removal of all dissolved species.

Conventionally treated wastewater contains a wide range of contaminants from suspended solids to the smallest of inorganic salts. Many of these are known or suspected to be detrimental to various reuse applications. A number of key contaminant categories are described in the following paragraphs.

Microorganisms represent the most common threat to the reuse of waste water, due the large concentration of potentially infectious species that routinely are present in the effluent of waste water from secondary treatment plants. The main purpose of membranes in water reuse schemes therefore is the retention of microorganisms. Most membrane processes provide a relatively effective barrier for all microorganisms, including viruses. This is true even for MF, which by pore size alone would not retain most viruses. However, the tendency of viruses to attach to other solids, aggregate with each other and the formation of a deposit on top of the actual filter lead to reduction factors around $10^{4}$ for bacteria and well over $10^{2}$ for viruses. However, such performance cannot be guaranteed for all times, due to malfunction, operator error or unnoticed loss of membrane integrity, and hence at least an additional disinfection step is considered necessary for uses where hygienic quality is critical.

Inorganic salts such as sodium chloride and a suite of trace elements including heavy metals may be introduced to irrigated pastures and associated waterways via recycled water. In dry climates, much of the irrigation water evaporates and the concentration of salts in the drainage can be much higher than in the water itself, posing potential threats to groundwater quality [6]. Salinity is already a major environmental problem in many parts of the world including Australia and care must be taken not to exacerbate this problem with inadequately treated recycled water.

An increasingly documented class of trace organic contaminants in wastewater are the "endocrine disrupting chemicals". Much attention has been devoted to natural and synthetic steroida hormones, which are shown to induce biological effects on some organisms at part per trillion concentrations. Some steroidal hormones are poorly removed in conventional water treatment processes. Other chemicals exhibiting similar effects at higher concentrations that are known to be present in sewages include some plasticisers, pesticides and degradation products of some detergents. According to state of the art knowledge, these substances pose a threat primarily to aquatic organisms and would not necessitate restrictions for many reuse applications.

Further widespread attention has been given to the broad range of pharmaceutically active compounds which have been reported in municipal wastewaters in many parts of the world $[7,8]$ At this point there are no indications for limitations to water reuse caused by these compounds, although here also the effect of compounds is largely unknown.

As in drinking water, by-products of disinfection processes may yet prove to be among the greatest chemical concerns in recycled water. Recent attention in the USA and Canada has been given to the detection of the potent carcinogen, nitrosodimethylamine (NDMA) in chlorinated sewages intended for reuse. NDMA is believed to be formed as a by-product of the disinfection process and can possibly be removed best by UV catalyzed oxidation [9].

It has previously been noted that we are technically capable of treating wastewater to any quality we desire simply by "filtering it through money". That is, in circumstances where money is no limitation, we may produce water with negligible levels of any contaminants. Membrane treatmen processes present a clear example of this correlation between quality and cost. In many circumstances, the high costs associated with very low porosity membranes will not be justifiable and relatively more porous membranes may be employed to produce reusable water of more limited quality. Further, even membrane processes are now showing limitations with regards to removing all contaminants (e,g. NDMA). Accordingly, the level of treatment applied will necessarily represent a compromise between the nature and concentration of contaminants and the associated treatment costs

In situations where water recycling guidelines exist or are in development, the setting of acceptable water quality standards will reflect these same compromises. The acceptable levels of contaminants will be determined by factors including the nature of the water reuse application and the economic and ecological situation of the region.

\section{Application of membrane processes in reclamation schemes}

3.1 Overview

Membrane processes are regarded as key elements of advanced wastewater reclamation and reuse schemes and are implemented in a number of prominent schemes world-wide including artificial groundwater recharge, indirect potable reuse as well as industrial process water production. Figure 
Wintgens, T. ; Melin, T. ; Schäfer, A. I. ; Muston, M. ; Bixio, D. ; Thoeye, C. (2005) The role of membrane processes in municipal wastewater reclamation and reuse, Desalination, 178, 1-11 doi:10.1016/j.desal.2004.12.014

2 illustrates identifiable water reuse schemes using membrane technology worldwide (to date 27 full scale installations have been recorded). The schemes are divided per size and type of beneficial use. Note that data on schemes "in planning or construction" and community facilities using membrane bioreactors (MBRs) are also available, but not reported in the Figure.

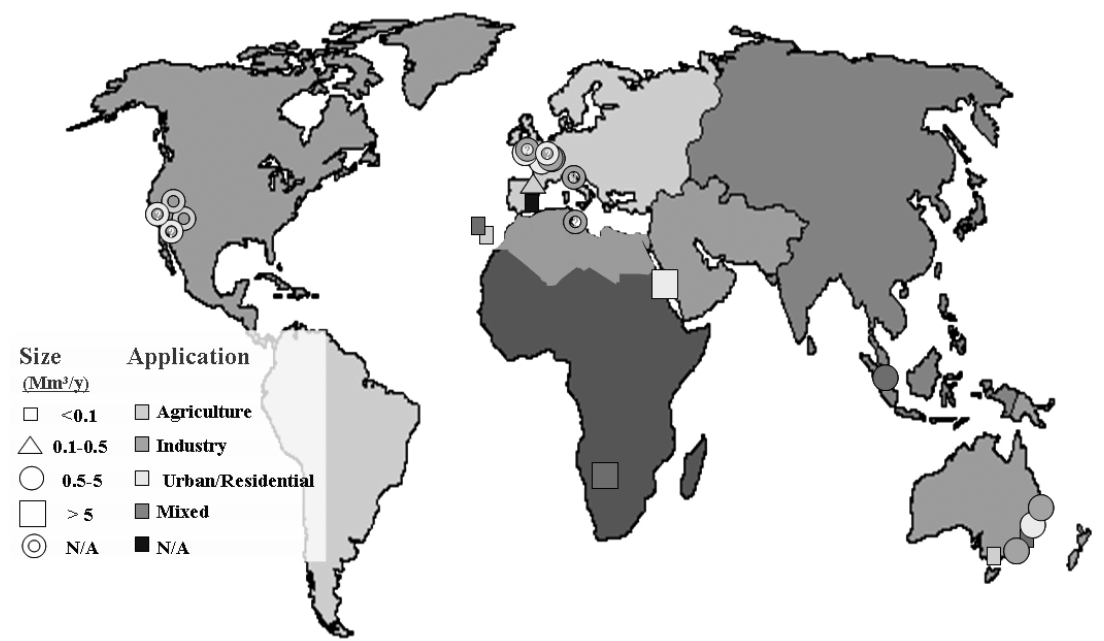

Figure 2: Existing water reclamation schemes using membrane systems worldwide

The map pictured in Figure 2 is destined to become outdated quickly. Many more projects are in an advanced planning phase. There is a clear trend for new larger scale plants to use dual membrane processes and MBRs.

As indicated in the previous chapter membrane processes are mostly applied as effluent polishing stages of municipal wastewater treatment plants, taking a secondary or tertiary effluent as feed with rather low suspended solids content, illustrated as option 1 in Figure 3. An alternative to this "endof-pipe" treatment is the application of MBRs as a straight combination of biological treatment processes and biomass retention by MF or UF membranes. MF and UF employed in tertiary wastewater treatment are dedicated to remove suspended solids, organic matter, and for disinfection, recovering a high quality final effluent with various possible uses. MF and UF technologies both in effluent filtration as well as in MBRs are also suitable as pre-treatment to NF or RO. Such physical barrier-processes are attractive in wastewater treatment because any technology employed must be able to produce reused water of uniform quality, regardless of the normally wide variation in the concentrations or physicochemical properties of the wastewater influent $[5,10,11]$ and the ansence of chemicals addition is of economic and ecological benefit.

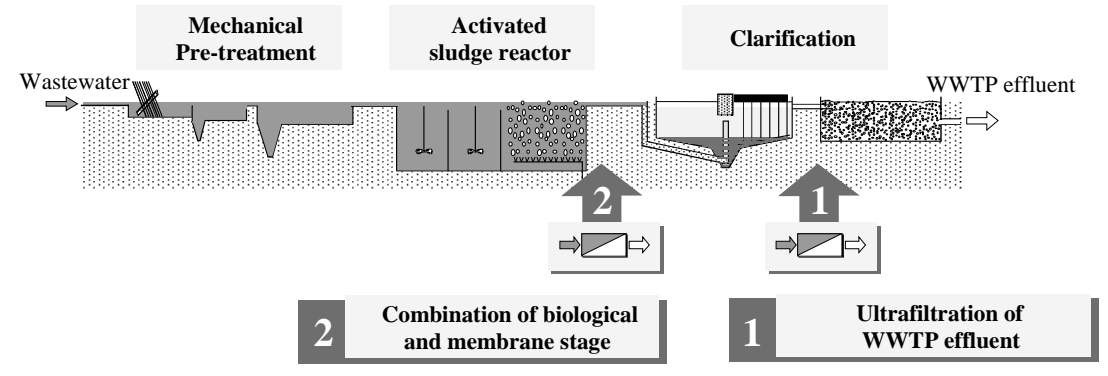

Figure 3: Application options for membranes in municipal wastewater treatment

Conductivity and dissolved oxygen content remain unaffected by both MF and UF treatment. The decolouration due to UF is more noticeable than that due to MF. Elimination of detergent and phenol concentrations of $40 \%$ were achieved by filtration. $\mathrm{Fe}, \mathrm{Zn}, \mathrm{Al}, \mathrm{Cr}, \mathrm{Cu}$ and $\mathrm{Mn}$ can also be significantly eliminated by filtration, not only by direct precipitation as hydroxides or phosphates, but also through association of metals to suspended matter and macromolecules.

It has been reported that microbial pollution is totally eliminated by MF and UF, explicable due to bacterial sizes being higher than pore sizes. However, as typically designed and operated in the field of wastewater treatment, UF cannot be considered a complete barrier to bacteria. Positive coliform results were obtained when membrane systems were operating. The passage of bacteria across membranes may be attributable to the following: imperfections in the membrane surface; degradation of the membrane by bacterial enzymes or other materials; or inferior packing of membrane modules or elements. Another possible reason for the detection of bacteria in membrane filtrate is the introduction of bacteria from exterior sources such as contamination of the permeate tank. Also, because nutrients are not eliminated from the water, re-emergence is best avoided through a disinfection process [ 12$]$.

MF and UF are effective in eliminating many wastewater contaminants associated with suspended matter. Elimination of viruses and nematodes accompanies to some extent removal of suspended matter. It has been demonstrated that viruses $(28 \mathrm{~nm})$ can be effectively retained by a $(0.2 \mu \mathrm{m}$ nominal pore size) MF membrane. Virus retention is enhanced at lower (trans-membrane) pressures, in the presence of shear and in the presence of biomass/turbidity. The latter both provides extra surface area for adsorptive removal and forms a secondary filter-cake layer on the membrane.

Coupled with powdered activated carbon (PAC), UF can be used to treat water contaminated by dissolved organic matter and micro-pollutants. In PAC-membrane processes, PAC is added to the recirculation loop of the membrane systems. Contaminants (including natural disinfection byproduct precursors) are adsorbed onto the activated carbon particles, which are then separated from water by either UF or MF $[13,14]$.

Because the quality of wastewater influent to MF and UF processes has a high influence on fina effluent quality, permeated water might be suitable for unrestricted irrigation purposes, as it is high in nutrients ( $\mathrm{N}$ and $\mathrm{P}$ practically insensitive to filtration), low micropollutant and microorganics content, and exhibits favourable inorganic ratios $[11,15,12]$. The application of UF to treat filtered secondary and secondary effluents may (as appropriate) be considered equivalent to an oxidized, 
coagulated, clarified, and filtered wastewater as per the Title 22 California Wastewater Reclamation Criteria [12].

Dense membrane processes (NF/RO) are capable of separating ions (and dissolved solids) from water. Separation relies to some extent on physico-chemical interactions between the permeating components and the membrane material. To an even greater extent than in the cases of MF and UF, the effective operation of NF and RO systems is dependent upon avoiding conditions leading to fouling, scaling or chemical interaction, hence affording extensive pre-treatment. In wastewater treatment and reclamation, RO systems are typically used as polishing processes having a significant impact on bulk parameters like $65-80 \%$ and $85-99 \%$ total organic carbon (TOC) removal with NF and RO, respectively. RO systems have been demonstrated to be effective in removing various contaminants of concern, including base neutral compounds, dissolved metals and pathogens $[16,17,18,19]$.

Pre-treatment of RO influent may involve combinations of some of the following [20]:

- flocculation / coagulation

- lime clarification

- sand filtration

- MF/UF

- UV and sodium hypochlorite disinfection

- anti-scalant addition

- $\mathrm{pH}$ adjustment

MF may provide significant cost savings and water quality improvement when replacing conventional lime pre-treatment for RO [21]. Also, MF can reduce microbial contamination and thereby reduce the rate at which fouling and biofilm formation occurs in subsequent RO. Although viruses are unlikely to pass through an RO membrane, leakage is possible (via glue strips or permeate seals) in spiral-wound elements. Thus, there is an incentive for virus removal at the pretreatment stage [15]. Use of capillary membranes as a pre-treatment for RO feed has enabled operation of cellulose acetate membranes at lower feed pressure and the production of water of lower salinity [22]. Anti-scalant addition is intended to minimise chemical precipitation on the RO membrane surface. It has also been reported as deemed necessary that MF effluent be dosed with sulphuric acid for $\mathrm{pH}$ adjustment to minimize hydrolysis of cellulose acetate RO membranes [19]. It is not uncommon for RO membranes in water reclamation applications to experience an average annual flux decline of $25-30 \%$, even with frequent membrane cleanings. It should be noted that membrane rejection properties are susceptible to change after cleaning [23]

3.2 Case studies

\section{Water Reclamation and Management Scheme (WRAMS) at Sydney Olympic Park, Australia}

The Water Reclamation and Management Scheme (WRAMS) at Sydney Olympic Park in Australia is an integrated water management project in an urban area. WRAMS includes use of treated sewage collected from within the site, supplemented where necessary by stormwater and with sewage pumped from outside the area, for non-potable reuse in and around Sydney Olympic Park. Included in the 760 ha supply area (including 425 ha of parkland) with a total permanent population of 7000 are large sporting and recreation facilities, hotels and commercial premises and the residential village of Newington.

The sewage is treated in a 2.ML/day capacity Sequencing Batch Reactor (SBR) process followed by UV. It is then treated in an advanced treatment plant with a maximum capacity of $7.5 \mathrm{ML} / \mathrm{day}$ using MF. Normally about $30 \%$ of the reclaimed water is then treated using RO to maintain the TDS at below $500 \mathrm{mg} / \mathrm{L}$ (mostly when supplemented with stormwater). The reclaimed water is chlorinated before distribution.

The reclaimed water is supplied by a separate "third pipe" distribution system with separate meters and colour coding of pipes and taps. A key management issue is the potential for cross connections and extensive checking was undertaken which lead to the detection and corrective action taken on two cross connections prior to the commissioning of pipe systems. The reclaimed water system operates at a lower pressure than the potable water supply to minimise the risk of polluting the potable supply if any cross connection occurs [24].

\section{Illawarra Waste Water Strategy in Wollongong, Australia}

The Illawarra Waste Water Strategy in Wollongong, Australia, due to be commissioned in early 2005 , includes a MF and RO advanced treatment plant with a capacity of $20 \mathrm{ML} /$ day treating low nutrient tertiary effluent from the Wollongong Sewage Treatment Plant. The reclaimed water from this advanced treatment plant will largely replace non-potable water requirements of the nearby Port Kembla integrated steel mill that are currently sourced from potable supplies. To minimise the impact on the industrial processes from blending or top up, the water quality from the advance water treatment plant is designed to match the (soft) water that is currently supplied from the nearby Avon Dam [25].

\section{Indirect potable reuse in Wulpen, Belgium}

In order to reduce the extraction of natural groundwater for potable water production and hold back the saline intrusion at the Flemish coast of Belgium, 2,500,000 $\mathrm{m}^{3}$ wastewater treatment plant effluent per year is infiltrated in the dunes after treatment with MF, RO and UV. The produced RO filtrate is reconditioned to match the natural salt content in the dune water. The recharged water is recaptured after a minimum residence time of 40 days in the dune aquifer. The drinking water quality standards are met; the recharge system performs as expected and resulted already in softer water adding to the comfort of the customers. The construction cost amounted to $€ 2.5$ million for the civil works and to $€ 3.5$ million for the electromechanical equipment [26]

\section{Groundwater Replenishment Scheme in Orange County, USA}

In order to supplement sources of water in Orange County, California clarified secondary effluent is reclaimed to produce water for a seawater intrusion barrier and for groundwater recharge. The Advanced Water Treatment (AWT) Facility has been commissioned in 2004 and consists of three major treatment processes; MF, RO, and an advanced oxidation process (AOP), which consists of UV light and hydrogen peroxide $\left(\mathrm{UV} / \mathrm{H}_{2} \mathrm{O}_{2}\right)$. This multi-barrier approach produces water with quality higher than other conventional water sources available to the Orange County area. The AWT facility will reclaim 70 million gallons per day (MGD) of OCSD clarified secondary effluent, normally disposed to the ocean. The plant may be expanded in the future to produce 130 MGD of product [27]. 
The full-scale demonstration facility proved that removal of all standard drinking water contaminants below regulated levels is possible with an advanced treatment process combining $\mathrm{MF}$, $\mathrm{RO}$, and AOP. UV/ $\mathrm{H}_{2} \mathrm{O}_{2}$ treatment is used for NDMA and other low molecular weight organic removal. After RO treatment, the product water is so low in mineral content that it is corrosive. This could be mitigated with the addition of lime.

\section{Membrane bioreactors for in-house water recycling in Japan}

According to Stephenson et al. [28] membrane bioreactor technology was proven to be very relevant in water reclamation and reuse, particularly in small-scale, decentralised applications e.g. in the densely populated urban in centres in Japan. The Japanese Government joined in 1989 with a number of the large companies to promote the development of a low footprint, high product quality treatment that would be suitable for wastewater reclamation and reuse. City legislation, such as in Fukuoka, required large buildings to adopt water saving measures including rainwater harvesting and in-building greywater treatment and reuse systems. This was partly demonstrated through the Aqua Renaissance program '90 [29] that led to development of systems such as the Kubota flatsheet submerged MBR and the Mitsubishi Rayon hollow fibre submerged MBR.

Two generic types of MBR have been used for in-building greywater treatment: initially these were sidestream systems, but more recently submerged systems have been introduced following their development by Japanese companies. Of the 500 operational MBRs identified by Stephenson $e t$ al . [30], almost $25 \%$ were used for in-building wastewater treatment, mostly in Japan. It was found that MBR generally provide significant advantages over alternative biological treatment processes in water recycling, particularly in terms of pathogen removal and process robustness [31, 32]

\section{Direct potable reuse in Windhoek, Namibia}

The only direct potable reuse project worldwide is operating to date in Windhoek/Namibia, one of the driest regions in Southern Africa. Having a several decades of experience in potable reuse the scheme underwent a significant refurbishment and the new Goreangab Water Reclamation project displaying a multi-barrier concept is in operation since 2002 [33]. Within this scheme secondary effluent $\left(21,000 \mathrm{~m}^{3} / \mathrm{d}\right)$ from a municipal wastewater treatment plant is reclaimed and treated to drinking water quality level by a complex treatment train including pre-ozonation, coagulation, dua media filtration, main ozonation, biological activated carbon adsorption and a two-stage granular activated carbon adsorption as well as UF prior to chlorine disinfection (see Figure 4). This treatment not only provides high quality water, it possesses multiple barriers for most microbial and chemical contaminants of concern and reduces the potential for disinfection by-product formation. The total operation cost of the water reclamation scheme are given at $0.76 \mathrm{US} \$ / \mathrm{m}^{3}$ [34]. Capillary UF membranes supplied by NORIT are used in the scheme and operated in dead-end mode (insideout) with an average permeate flux of $107 \mathrm{~L} / \mathrm{m}^{2} \mathrm{~h}$ at a transmembrane pressure of 0.4-0.7 bar [35].

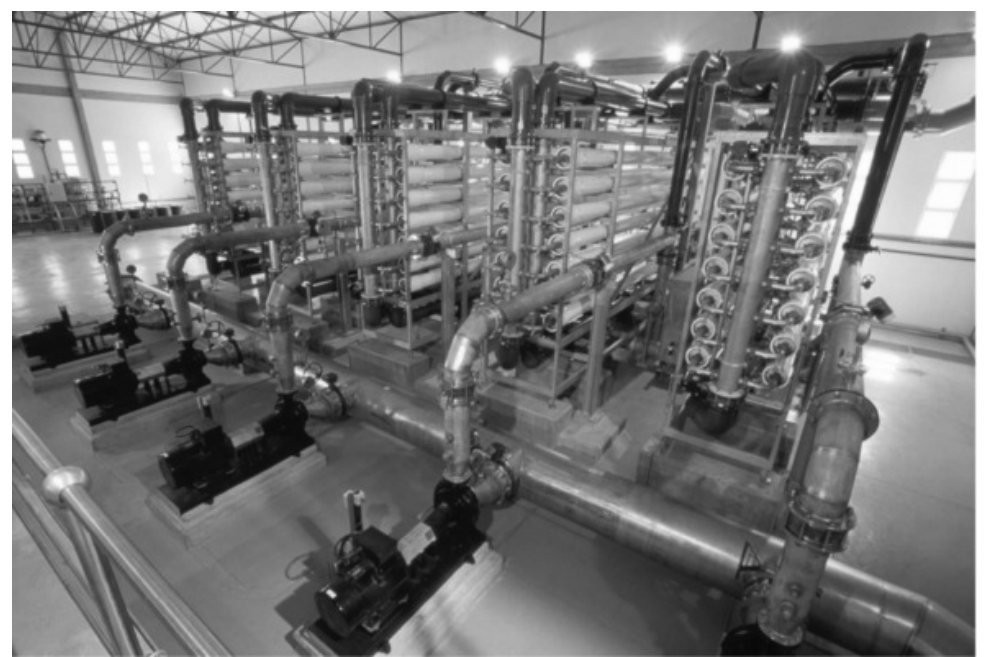

Figure 4: Membrane filtration racks at Windhoek/Namibia (reproduced with permission [33]) Indirect potable reuse - the NEWater Project, Singapore

As part of the sustainable water supply programme the NEWater Project was implemented in Singapore to supplement freshwater resources used for drinking water production from reclaimed water. Since January 2004 the third water reclamation plant is in operation increasing the overall NEWater capacity to $91,000 \mathrm{~m} / \mathrm{d}$. The reclamation process involves a double-membrane treatment of secondary effluent with MF and RO and final disinfection by UV. Chlorine is dosed before and after the MF to control biofouling. The RO units provide an excellent product quality with TOC and TDS removal $>97 \%$ making the reclaimed water also suitable for use in the semiconductor industry [36]. The MF consists of a submerged hollow fibre system supplied by ZENON [37]. The RO units are supplied by Hydranautics and based on thin film aromatic polyamide composite membranes [38].

\section{Summary, conclusions and future trends}

Membranes have been assigned a key role in water reclamation schemes that are aimed at higher water quality reuse applications. Typically, these applications include aquifer recharge, indirect potable reuse, dual water systems in households and industrial process water. UF and MF are employed as preferred processes for microbial retention and as pretreatment for NF or RO, which then are able to generate drinking water or process water quality. Based on seven examples from five continents, we have tried to describe some of the most important concepts that are in operation around the globe. Up to now, almost all large schemes have been designed as add-on technology to conventional secondary treatment schemes.

It is expected, however, that in the future more often membranes will be integrated into secondary treatment, as has been done routinely in decentralized systems in buildings (Japan) and on ships using membrane bioreactors (MBRs). 
Consequently and as an example, "membrane bioreactors" are also a topic designated by the European Commission as priority research target in a 2004 call of the $6^{\text {th }}$ Framework Programme. The rapid growth of membrane technology in the field of water reclamation is expected to continue, leading to a significant decline in infrastructure and operating costs for such reclamation systems.

Future development will also have to include on-line quality control of membrane processes. As long as integrity failures can go undetected for longer times, relatively expensive dual or multiple barrier systems will be required for all those applications that require guaranteed drinking water quality at all times.

\section{Acknowledgements}

The authors acknowledge the European Commission for funding this work within the AQUAREC project on "Integrated Concepts for Reuse of Upgraded Wastewater" (EVK1-CT-2002-00130) under the Fifth Framework Programme contributing to the implementation of the Key Action "Sustainable Management and Quality of Water" within Energy, Environment and Sustainable Development thematic programme. This work is also proudly supported by the International Science Linkages programme established under the Australian Government's innovation statement Backing Australia's Ability. It is funded by the Commonwealth Department of Education Science and Training for the project OzAquarec: Integrated Concepts for Reuse of Upgraded Wastewater in Australia (CG030025).

\section{References}

1. Bixio D., De heyder B., Chikurel H., Muston M., Miska V., Joksimovic D., Schäfer A.I., Ravazzini A., Aharoni A., Savic D. and C. Thoeye. In: Proc. $4^{\text {th }}$ IWA World Congress; 19-24 September 2004, Marrakech, Morocco.

2. Anderson J., Adin A., Crook J., Davis C., Hultquist R., Jimene-Cisneros B., Kennedy W., Sheikh B., van der Merwe B. Wat. Sci. Tech. 4310 (2002) 1-8.

3. Friedler E. Wat. Policy 3 (2002) 29-39.

4. Lens P., Hulshoff Pol L., Wilderer P., T. Asano. Water Recycling and Resource Recovery in Industry (Analysis, Technologies and Implementation), 2002.

5. Wastewater Engineering: Treatment, Disposal and Reuse. 3rd edition, Metcalf \& Eddy, Inc., McGrawHill, Inc., ISBN 0-07-041690-7, 1991.

6. Bouwer, H. Groundwater problems caused by irrigation with sewage effluent. J. Environ. Health 633 (2000) $17-20$.

7. Andreozzi, R., Raffaele, M. and Nicklas, P. Chemosphere 5010 (2003) 1319-1330.

8. Huggett, D. B., Khan, I. A., Foran, C. M. and Schlenk, D. Environ. Pollut. 1212 (2003) 199-205.

9. Mitch, W. A. and Sedlak, D. L. Water Supply, 23 (2002) 191-198.

10. Adin A., Asano T. Wat. Sci. Tech 3710 (1998) 79-90.

11. Alonso E., Santos A., Solis G.J., Riesco P. Desal. 141 (2002) 39-51.

12. Bourgeous K., Darby J., Tchobanoglous G. Wat. Res. 351 (2001) 77-90.

13. Zhou H., Smith D. J. Environ. Eng.Sci. 1 (2002) 247-264.

14. Laîné J.-M., Vial D., Moulart P. Proceedings of the Conference on Membranes in Drinking and Industrial Water Production, Volume 1, 17-25, ISBN 0-86689-060-2, October 2000, Desalinatio Publications, L'Aquila, Italy.

15. Sadr Ghayeni S., Madaeni S., Fane A., Schneider R. Desalination 106 (1996) 25-29.

16. Van Gauwbergen D., Baeyen J. Wat. Sci. Tech. 40 4-5 (1999) 269-276.

17. Levine B., Reich K., Shields P., Suffet I., Lazarova V. Wat. Sci. and Tech. 4310 (2001) 249-257.

18. Levine B., Madireddi, Lazarova V., Stenstrom M., Suffet M.. Wat. Sci. Tech. 40 4-5 (1999) 293-301.
19. Adham S., Gagliardo P., Smith D., Ross D., Gramith K., Trussell R. Desal. 119 (1998) 143-150.

20. López-Ramírez J., Sahuquillo S., Sales D., Quiroga J. Wat. Res. 37 (2003) 1177-1184.

21. Lazarova V., Shields P., Levine B., Savoye P., Hranisavljevic D., Renaud P. Wat. Sup. 33 (2003) $167-$ 175

22. Wilf M., Alt S. Desal. 132 (2000) 11-19.

23. Wilf M., Alt S. Desalination Research and Development Report No.42, U.S. Department of Interior, Bureau of Reclamation, June 1999

24. Listowski A., MacCormick A. Proceedings Enviro 04 Conference Sydney Australia, Australian Water Association, April 2004

25. Standon G. Sydney Water Corporation, Personal Communication, 2004

26. van Houtte E. and J. Verbauwhede. Proc. Aquarec Workshop; Thessaloniki, Greece; 11-12 March 2004

27. Deshmukh S. Proc. Aquarec Workshop; Thessaloniki, Greece; 11-12 March 2004.

28. Stephenson T., S. Judd, B. Jefferson. Membrantechnik in der Wasseraufbereitung und Abwasserbehandlung. T. Melin and M. Dohmann (Eds.), ISBN 3-921955-28-9, 2004

29. Kimura S. Wat. Sci. Tech. 23 7-9 (1991) 1573-1582.

30. Stephenson T., S, J. Judd, B. Jefferson, and K. Brindle, Membrane Bioreactors for Wastewater Treatment. IWA Publishing, London. 2000, 179pp.

31. Jefferson B., A. Laine, T. Stephenson and S. J. Judd. Wat. Sci. Tech. 4310 (2001) 211-218.

32. Palmer A., B. Jefferson, P. Jeffrey and S. J. Judd. Proceedings of the International Water Association Biennial Congress (2002) Melbourne, Australia, 9pp.

33. City of Windhoek (2004): http://www.windhoekcc.org.na/Default.aspx?page $=118$

34. Lahnsteiner J., Sevitz D., Lempert G. (2004) Potable Reuse in Windhoek/Namibia.

35. NORIT Membrane Technology (2003) New Goreangab Water Reclamation Plant, Windhoek (Namibia).

36. Newater (2004) http://www.pub.gov.sg/NEWater_files/overview/index.html

37. Zenon (2002) http://www.zenonenv.com/investor/news/Nov2502.shtm

38. Krüger R. Membrantechnik in der Wasseraufbereitung und Abwasserbehandlung. T. Melin and M. Dohmann (Eds.), ISBN 3-921955-28-9, 2003. 